\title{
Impact of training in the elderly: the case of the Open Classroom for the Elderly
}

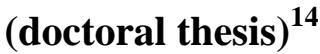

\author{
José Luis Rodríguez Díez \\ jlrdiez@gmail.com
}

Directores: Pérez de Guzmán Puya, M. V., Amador Muñoz, L. V., \&

Moreno Crespo, P. A.

\section{Summary}

The Senior Survey (2010) stated that in Spain 60\% of people start new activities after retirement. One of the demands of this new generation of seniors is a quality university education. The purpose of this study was to investigate the impact of training in the elderly, in a formal educational context, taking into account the social and psychological dimensions. The work is structured in two sections: theoretical foundations and empirical framework.

\section{Theoretical foundation}

This section is organized into four chapters. The first, called "Approaching the concept of old age", is a review of the definitions of old age and the origin of the various terms used to designate this evolutionary stage in life and its implications. This study makes an approach to the elderly through history, mainly in Europe, as well as its current and future vision. A review of legislation and relevant documents both internationally and of the Autonomous Community of Andalusia (Spain) about this vital life stage is performed. Various theoretical models are presented in order to explain aging, devoting

\footnotetext{
${ }^{14}$ Recibido:25/11/2015 Evaluado:01/12/2015 Aceptado:06/12/2015
} 
a section to retirement, that in fact represents a turning point in the lives of people, especially those over 65 years old, which is the official beginning of old age stage.

The second chapter, "Old age as an object of study", presents an evolutionary research on the study of old age and aging by a summarization of the work carried out in geriatrics, gerontology and psycho-gerontology. The psychological and social dimensions were studied in depth, incorporating family life and the participation of older adults, because these two dimensions were the factors studied in this investigation.

"Learning throughout life" is the third chapter of this study, which presents a reflection on learning throughout life and its evolution from the beginning of adult literacy. It describes in detail the theoretical approaches utilized in adult learning. The symbiosis between quality of life and active aging is presented in this chapter, as well as the approach to gerontology, as a scientific and professional area dedicated to socioeducational intervention with and for older people.

The fourth and final chapter of the theoretical foundations, called "Training programs for older adults," analyzes in depth the various programs for older adults, with their respective characteristics. It focuses on university programs for older adults, with a description of the formative models. Finally, it makes a deep analysis of the program "Open Classroom for the Elderly" at the University Pablo de Olavide in Seville, which was the object of research for this study. We finish with the most relevant legislation on adult education.

\section{Empirical framework}

The research focused on an analysis of the influence of the training received by students who attended the" Open Classroom for the Elderly" at the University Pablo de Olavide. The objectives of the study revolved around the psychological and social dimension of older adults, highlighting first the personal aspect, and second the family aspect and participation aspect that were influenced by their participation in this project. From these three aspects or dimensions, fifteen specific objectives were developed for this study. The objective that was related to the personal aspect aimed to describe the selfimage and self-perception that adults had. The objective, focused on the family aspect, 
tried to investigate the importance of elders as family support. The last objective related to the social aspect, analyzed the participation of seniors in the Open Classroom for the Elderly. The methodology used was of a mixed nature. From a quantitative perspective, the selected method of research design was a quasi-experimental, called causalcomparative or "ex-post-facto" design or single case and the choice to analyze the sample used was a casual non-probability statistical method.

\section{Conclusions}

The results showed, in general, how the attendance to this educational training program for older adults at the university level is related to:

On a personal level, they improve self-esteem, self-perception and the sense of belonging to the same group and diminish the feeling of rejection. Also, they consider that there was qualitatively difference with respect to those over the previous generation.

In the family, they have improved their relations by providing more objectivity when it comes to solving problems and enabling them to discover that training throughout life is as important as its work in the family.

In the social sphere, they are proud to belong to the Open Classroom and the University, increasing its expectations for training throughout life and creating a need for further training when his participation in the training program. 